\title{
Balancing nutrition, luxury, and time constraints in food preparation choices
}

\author{
Sanae Tashiro
}

Rhode Island College, Providence, Rhode Island, USA, and

Chu-Ping Lo

National Taiwan University, Taipei, Taiwan

\begin{abstract}
Purpose - The purpose of this paper is to examine how nutritional concerns, luxurious tastes, and the value of time affect time allocation decisions for food preparation.

Design/methodology/approach - A time allocation model is developed and tested with Tobit and Heckman's sample selection models using the 2003-2007 American Time Use Survey data.

Findings - Individuals concerned more with nutrition or price than luxury devote more time to preparing food-cooked-at-home. High family income and long hours worked increase time allocated to food-away-from-home, indicating that a preference for luxury and the opportunity cost of time outweigh nutritional concerns. High education reduces time spent preparing food-cooked-at-home, yet increases both participation in this activity and time spent obtaining food-away-from-home, suggesting that a preference for luxury and the opportunity cost of time dominate nutritional preference. Time allocation decisions on food preparation vary greatly by race and ethnicity.

Originality/value - The results of this study confirm that the time allocation decisions regarding food preparation are largely affected by an individual's luxury preference, nutritional consciousness, and the value of time, all of which are influenced by education. The findings from this study indicate factors that influence consumers' time allocation decisions regarding food choice and their current food preparation behavior, and thus provide useful insights to nutritionists, dietitians, health practitioners, and policy makers for finding better ways to improve nutritional education, food choices and dietary habits that promote healthier diets and eating habits.
\end{abstract}

Keywords Individual behaviour, Diet, Cooking, Food products

Paper type Research paper

\section{Introduction}

Food selection, including food-cooked-at-home, prepared-food, and food-away-from-home, is not only influenced by the value of the homemaker's time (Prochaska and Schrimper, 1973; Becker, 1965) but also by socio-economic factors, such as household income (Glanz et al., 1998; Popkin et al., 1996; Turrell, 1996; Kinsey, 1994). Individuals with long market hours plus a high market wage may spend less time cooking at home or eating out, substituting prepared-foods from retail stores (Carlson et al., 2002; McCracken and Brandt, 1987). The demand for convenience foods is increasing not only in the USA (Martinez and Stewart, 2003) but also in Asian countries, such as China (Curtis et al., 2007; Veeck and Veeck, 2000) and Japan (Campo and Beghin, 2006). High-income households rely more on food-away-from-home (McCracken and Brandt, 1987), while low-income households are likely to depend on

JEL classification - J01, J16, J22

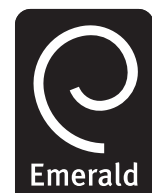

China Agricultural Economic Review

Vol. 3 No. 2, 2011 pp. $245-265$ (C) Emerald Group Publishing Limited 1756-137X DOI $10.1108 / 17561371111131344$ 
CAER

3,2

246 food-cooked-at-home (Blisard and Stewart, 2007). Recent income growth, for example, has increased the consumption of food-away-from-home in China (Ma et al., 2006).

Concern about nutrition (which relates to health) and a preference for luxury consumption (which reflects wealth) also influence one's food selection and food preparation choices. Nutrition-conscious individuals may trade-off between luxury and nutrition, and are more likely to consume food-cooked-at-home (Stewart et al., 2005), for which they can obtain nutritional information, control ingredients, and manage nutritional values (Nayga et al., 1998), and thus they allocate more time to cooking at home. For example, older people who place a high value on nutrition, spend more time shopping for groceries (Aguiar and Hurst, 2007) and consume more food-cooked-at-home (Binkley, 2006; Blisard et al., 2002; Glanz et al., 1998; Glanz et al., 1994), and thus they spend more time on cooking at home (Aguiar and Hurst, 2007). Luxury-conscious individuals, on the other hand, may trade-off between price (or nutrition) and luxury, and they prefer to consume more food-away-from-home prepared by a restaurant or other food vendor, thereby not only consuming food but also enjoying other services (Ma et al., 2006; Darian and Klein, 1989), and thus they allocate more time to dining outside home. Wealthier people (Blisard and Stewart, 2007; Yen, 1993; Lee and Brown, 1993) and highly educated people (Stewart and Yen, 2004) consume more food-away-from-home and, in turn, they spend more time dining out.

The time that individuals allocate to their food selection is a topic of growing interest among researchers, managers and practitioners in the food and health care industries, as well as among policy makers, because it affects our diet, health and well-being. How do nutritional preferences, luxurious tastes, and the value of time impact the allocation of time to food preparation? How do individuals make trade-offs in food preparation between nutrition, luxury and price? How do socio-economic factors, such as education or family income, influence individuals' nutritional and/or luxury preferences and how do they affect food preparation choices? This paper examines these questions by focusing on the choice between food-cooked-at-home and food-away-from-home. The theoretical framework models the allocation of non-market hours to food preparation choices, and Tobit and Heckman's sample selection models estimate the proposed questions using the 2003-2007 American Time Use Survey (ATUS) data.

First, this study finds that family income and hours worked per day are negatively related not only to the likelihood of selecting food-cooked-at-home but also to the actual time spent on this activity. Both individuals who have a high preference for luxury (as a result of high income) and those who face a high value of time (due to long market hours) are likely to reduce their frequency of preparing food-cooked-at-home as well as their time spent preparing it. Education increases the probability of preparing food-cooked-at-home, but it reduces the actual time spent on this activity. This result indicates that a preference for nutrition increases with education, but a high value of time reduces the allocation of time to food-cooked-at-home. On the other hand, age, female gender, and household size are positively related to both the probability of selecting food-cooked-at-home and the actual time spent on this activity. Both elderly people who are more health conscious and thus value nutritional concerns and large-member households who aim for economies of scale in home production are likely to prepare more food-cooked-at-home and spend more time on this activity. Asians and Hispanics also increase their time spent preparing food-cooked-at-home, which may reflect the fact that they are more cost conscious and/or follow cultural traditions to eat at home with family. 
This study also shows that household size, female gender, and Black race are negatively related to both the likelihood of selecting food-away-from-home and the actual time spent on dining out. Time-and/or budget-constrained individuals are likely to reduce their eating-out occasions and to spend less time obtaining food-away-from-home. Conversely, education (that increases market wages) and family income, both of which increase taste for luxury, increase both the frequency of selecting food-away-from-home and the time spent obtaining it. Age reduces one's probability of selecting food-away-from-home, while hours worked per day increase it; Food preparation choices however, the relationship between age and the actual time spent obtaining food-away-from-home is rather unclear. Whites, Asians, and Hispanics showed no effect.

This paper extends existing studies on household food consumption by incorporating a time constraint in addition to a budget constraint and shows that both participation and time allocation decisions regarding food preparation are largely affected by nutritional concerns, luxurious tastes, and the value of time, all of which are influenced by education. The results of this study also present factors that influence time allocation decisions regarding food choice, offer additional findings, insights, and implications for understanding our food choices better in the modern era, and thus provides useful insights to assist food manufacturers and retailers, nutritionists, dietitians, health practitioners, and policy makers in identifying ways to improve diets and health. The findings of this study are also useful for developing nutritional education program in any Asian countries, such as China, that are increasingly adopting Western-style food and average caloric intakes.

\section{The model}

We develop a theoretical model to examine how individuals allocate non-market hours to food preparation, with specific attention to their choice between food-cooked-at-home and food-away-from-home, while facing both time and budget constraints. Assume that the household maximizes utility and that all households have identical preferences, represented by:

$$
U=\left(l_{0}+t_{k} k\right)+\beta k^{\theta}\left(n^{\alpha} m^{1-\alpha}\right)^{1-\theta},
$$

where $k$ is the number of food-away-from-home meals, which mainly refers to restaurant meals and those purchased from other food vendors in the market, $n$ is the number of food-cooked-at-home meals, and $m$ is the number of "all other foods", which include prepared-food meals. The parameter $\beta$ measures the weight that a household places on consumption relative to leisure. Here, we assume that leisure is the sum of recreation hours as $l=l_{0}+t_{k} k$, where $l_{0}$ denotes other types of recreation, and $t_{k}$ denotes the number of hours spent obtaining food-away-from-home. We argue that food-away-from-home not only provides food but also other services to consumers, such as relaxation and socialization (Ma et al., 2006; Darian and Klein, 1989), so that food-away-from-home in this model includes a leisure component.

The parameter $\alpha$ in equation (1) indicates the preference for nutrition, and thus $\alpha$ is larger when the household is more nutrition-conscious. It is feasible to argue that prepared-food is the least nutritious, followed by food-away-from-home and food-cooked-at-home[1]. Further, we use the parameter $\theta$ in equation (1) to indicate the preference for luxury or leisure, and the value of $\theta$ is larger when the household is more luxury-conscious. It is reasonable to argue that food-cooked-at-home is the 
CAER

3,2

248

least luxurious (and the least leisurely), followed by prepared-food and food-awayfrom-home.

The price of meals provided by restaurants (i.e. food-away-from-home) is usually higher than both the price of food-cooked-at-home and the price of "all other foods" (e.g. prepared-food). The price of food-cooked-at-home, on the other hand, is not significantly different from that of prepared-food. Thus, we assume that the trade-off between food-cooked-at-home and "all other foods" is mainly driven by one's nutritional concerns. Contrarily, the trade-off between food-away-from-home and food-cookedat-home (or "all other foods") is not only driven by one's nutritional concerns but also by luxurious tastes. Given that, the utility function in equation (1) indicates that the marginal rate of substitution between food-cooked-at-home and "all other foods" relies on the preference for nutrition only, while that between food-away-from-home and food-cookedat-home (or "all other foods") relies on preferences for both nutrition and luxury.

Both preferences for nutrition $(\alpha)$ and for luxury $(\theta)$ are largely influenced by one's educational attainment. For example, education increases one's nutritional concern and health knowledge (Rimal, 2002; Ramezani and Roeder, 1995; Carlson and Gould, 1994; Redman, 1980) and has a large positive effect on one's desire for luxury (or taste) in food (Pietrykowski, 2004; Horton and Campbell, 1991). We thus use education as a proxy to measure one's preferences for nutrition $(\alpha)$ and luxury $(\theta)$.

The representative household faces this budget constraint:

$$
I=l_{w} w=N\left(p_{n} n+p_{m} m+p_{k} k\right)
$$

where $p_{n}, p_{k}$, and $p_{m}$ are the prices of food-cooked-at-home, food-away-from-home, and "all other foods", respectively. Food-cooked-at-home incurs the costs of raw materials (e.g. groceries) and non-market hours to prepare them, while prepared-food incurs the costs (or the wages) of food-preparers and non-market hours to obtain it. We assume that the price of prepared-food is higher than that of food-cooked-at home $\left(p_{n} \leq p_{m}\right)$. Further, food-away-from-home incurs the costs (or the wages) of both food-preparers and servers as well as non-market hours to obtain it, so the price of food-away-from-home is the highest $\left(p_{n} \leq p_{m}<p_{k}\right)$. Here, $l_{w}$ denotes the work hours of the household, and $w$ is the exogenous wage rate, which positively relates to an individual's human capital (or education). Further, $N$ in equation (2) denotes family size, and a larger family consumes more meals proportionately than a smaller family.

A representative household is endowed with $T$ amount of time, which is allocated to work, leisure, and food preparation. The time constraint is given by:

$$
T=l+l_{w}+n t_{n}=l_{w}+l_{0}+t_{k} k+n t_{n}(N),
$$

where $t_{n}(N)$ denotes the amount of time required to prepare food-cooked-at-home, which is a function of family size. It is feasible to assume that the time spent preparing food-cooked-at-home is increasing at diminishing rate with respect to family size (i.e. $t_{n}^{\prime}(N)>0$ and $t_{n}^{\prime \prime}(N)<0$ ). Further, time spent purchasing prepared-food is negligible in comparison to time spent preparing food-cooked-at-home or obtaining food-away-from-home, and thus we neglect the time spent purchasing "all other foods" in equation (3)[2].

With budget constraint (2) and time constraint (3), the Lagrangian function is given by[3]: 


$$
\begin{aligned}
L= & \left(l_{0}+t_{k} k\right)+\beta k^{\theta}\left(n^{\alpha} m^{1-\alpha}\right)^{1-\theta}+\lambda_{1}\left[w l_{w}-N\left(p_{n} n+p_{m} m+p_{k} k\right)\right] \\
& +\lambda_{2}\left(T-l_{w}-l_{0}-t_{k} k-t_{n} n\right)
\end{aligned}
$$

The first-order conditions of the Lagrangian function with respect to $n, m$, and $k$ are:

$$
\begin{gathered}
\alpha(1-\theta) \beta n^{\alpha-1} m^{1-\alpha} k^{\theta}\left(n^{\alpha} m^{1-\alpha}\right)^{-\theta}=N \frac{p_{n}}{w}+t_{n}(N), \\
(1-\alpha)(1-\theta) \beta n^{\alpha} m^{-\alpha} k^{\theta}\left(n^{\alpha} m^{1-\alpha}\right)^{-\theta}=N \frac{p_{m}}{w}, \text { and } \\
\theta \beta k^{\theta-1}\left(n^{\alpha} m^{1-\alpha}\right)^{1-\theta}=N \frac{p_{k}}{w}+t_{k}, \text { respectively. }
\end{gathered}
$$

From equations (4) and (5), we obtain:

$$
\frac{m}{n}=\left(\frac{1-\alpha}{\alpha}\right)\left(\frac{p_{n}}{p_{m}}+\frac{w}{p_{m}} \frac{t_{n}(N)}{N}\right),
$$

where $w t_{n}(N)$ denotes the opportunity cost of preparing food-cooked-at-home, and $N p_{n}$ denotes the actual cost of preparing food-cooked-at-home. Note that the $\alpha$ in the first bracket of equation (7) represents nutritional preference, and we observe that a household consumes more food-cooked-at-home relative to "all other foods" (e.g. prepared-food) when the household is more nutrition-conscious (i.e. $\mathrm{m} / \mathrm{n}$ decreases with $\alpha$ ). Additionally, the relative demand for "all other foods" compared to food-cooked-at-home decreases with an increase in their relative prices, but increases with the opportunity cost of preparing food-cooked-at-home. Further, the relative demand for "all other foods" compared to food-cooked-at-home decreases with family size, indicating that households spend more time preparing food-cooked-at-home as family size increases[4].

From equations (4) and (6), we obtain:

$$
\frac{k}{n}=\left(\frac{\theta}{\alpha(1-\theta)}\right)\left(\frac{N p_{n}+w t_{n}(N)}{N p_{k}+t_{k}}\right) .
$$

Similarly, $k / n$ in equation (8) decreases with family size $N$, implying that households spend more time preparing food-cooked-at-home (rather than obtaining food-away-from-home) as family size increases. Equation (8) also implies that a household that places a high value on luxury or leisure (i.e. a larger $\theta$ ) and is insensitive about both price of meals and nutrition, and thus consumes more food-away-from-home relative to food-cooked-at-home.

From equations (5) and (6), we obtain:

$$
\frac{k}{m}=\left(\frac{\theta}{(1-\alpha)(1-\theta)}\right)\left(\frac{N p_{m}}{N p_{k}+w t_{k}}\right) .
$$

Equation (9) implies that a household that places more value on luxury or leisure (i.e. a larger $\theta$ ) and/or that is price-insensitive will consume more food-away-from-home than "all other foods". We also observe that when a household is more nutrition-conscious (i.e. a larger $\alpha$ ), it will consume more food-cooked-at-home compared to "all other foods" (i.e. $\mathrm{k} / \mathrm{m}$ becomes larger). 
CAER

3,2

250
From equations (8) and (9), we can make the following predictions. First, a household that places a high value on nutrition (i.e. a larger $\alpha$ ) and which has a high level of education, will consume more food-cooked-at-home (rather than food-away-from-home and "all other foods") relative to a household that places a low value on nutrition and which has a low level of education. Second, a household that faces a larger opportunity cost of time for food preparation at home, and/or one that has a high preference for luxury or leisure (i.e. a larger $\theta$ ), will consume more food-away-from-home relative to a household that faces a lower opportunity cost of time for food preparation at home and/or that sets a low value on luxury.

Hence, the time-allocation decision regarding food preparation may depend on the magnitude of preference that the household places on nutrition $(\alpha)$ and luxury $(\theta)$, and on which of these two is dominant - reflecting trade-offs between nutrition and taste (Blaylock et al., 1999). We also argue that household income and the value of a homemaker's time affect preferences for both luxury and nutrition, and, in turn, influence the time-allocation decision of individuals regarding food preparation choices.

\section{Data}

The primary interest of this paper is to examine how individuals allocate non-market hours to food preparation, with specific attention to their choice between food-cooked-at-home and food-away-from-home, while facing both time and budget constraints. We thus use the multi-year ATUS data for the years 2003-2007, which combine microdata from 2003 to 2007[5]. This multi-year ATUS data measure how Americans allocate their time among life's activities. The ATUS respondents are randomly selected from individuals that have completed their eighth and final month of interviews for the Current Population Survey (CPS) and are interviewed only once about how they spent their time.

The multi-year micro data that are used in this paper have three sources:

(1) the 2003-2007 ATUS respondent file;

(2) the 2003-2007 ATUS activity summary file; and

(3) the 2003-2007 ATUS-CPS file.

The ATUS respondent file contains one record per individual with information about the respondents, including their demographic status (such as age, sex, race, ethnicity, educational attainment, marital status, metropolitan living status, wage, weeks worked, occupation, and industry). The ATUS activity summary file has information collected in the ATUS diary, with over 400 categories of time use, and contains ATUS respondents' detailed accounts of the total number of minutes spent on each activity during the diary date for a 24-hour window, starting at 4 a.m. on the day before the interview and ending at 4 a.m. on the day of the interview[6]. The 2003-2007 ATUS-CPS file gathers one record per household member for all households in which an individual participates in the ATUS and contains each household member's demographic status.

The 2003-2007 ATUS data, gathered from three linked ATUS files using information on the ATUS-CPS file, contains 72,922 respondents and includes household members aged 15 and older. In this paper, we focus on individuals aged 18-65 at the survey date. After restrictions, the sample size falls to 57,708 (25,370 men and 32,338 women). In addition to the full respondent sample, we use a data sample separated by the total number of household members: 
(1) one-person households;

(2) two-member households; and

Food preparation choices

(3) more-than-two-member households.

Categories of interest in this paper are time spent preparing food-cooked-at-home, time spent obtaining food-away-from-home, and the socio-demographic status of respondents[7]. Further, we focus on the primary activities of respondents.

\section{Descriptive analysis}

This section summarizes the data on selected characteristics and the average time spent (in minutes per day) on selected daily activities of survey respondents at both the individual and the household levels. The individual level sample contains information collected from those who completed the survey and is defined as the full respondent sample. The household level sample contains information on the respondents' households, and is divided into three categories:

(1) one-person households;

(2) two-person households; and

(3) more-than-two-person households.

Table I shows selected characteristics of survey respondents. Within the full respondent sample, about 50 percent are in ages $26-45$, about 40 percent are $46-65$, and the remaining 10 percent are 18-25. Note that standard errors are shown in parentheses. One- and two-person households are concentrated in ages 46-65 and more-than-two-person households are mostly in ages 26-45. In the full respondent sample, 44 percent is male and the remaining 56 percent is female, and the distribution is similar for more-than-two-person households. However, the proportion of males increases to 48 percent and that of females declines to 52 percent for one-person households. Across all samples, approximately 25-30 percent of the population has a high school diploma, followed by 20-22 percent with a Bachelor's degree. About 11-13 percent of the population holds an advanced (Master's, professional, or doctoral) degree and 9-13 percent holds less than a high school diploma. Approximately, 21 percent of the population in the full respondent sample reported household incomes of less than $\$ 25,000$, while 28,21 , and 18 percent of the population earned $\$ 25,000-49,999$, $\$ 50,000-74,999$, and $\$ 75,000-99,999$, respectively, and the remaining 12 percent earned more than $\$ 100,000$. The distribution is similar for two-person households; however, one-person households are most likely to earn household incomes of less than $\$ 50,000$, whereas more-than-two-person households earn higher incomes than other households. About 42 percent of the population in the full respondent sample is unmarried, and the percentage of unmarried respondents increases as the number of household members decreases. Over 80 percent of the population lives in metropolitan areas.

Table II provides the weighted average time spent on selected daily activities for survey respondents at both the individual level and the household level. Note that again standard errors are shown in parentheses. We use the weighted average time spent to analyze how individuals allocate their time across the daily activities since a simple tabulation of unweighted ATUS data produces either upward or downward biased results. The weighted average time spent on each activity is calculated using 


\section{CAER \\ 3,2}

\section{2}

Table I.

Selected characteristics of individual respondents

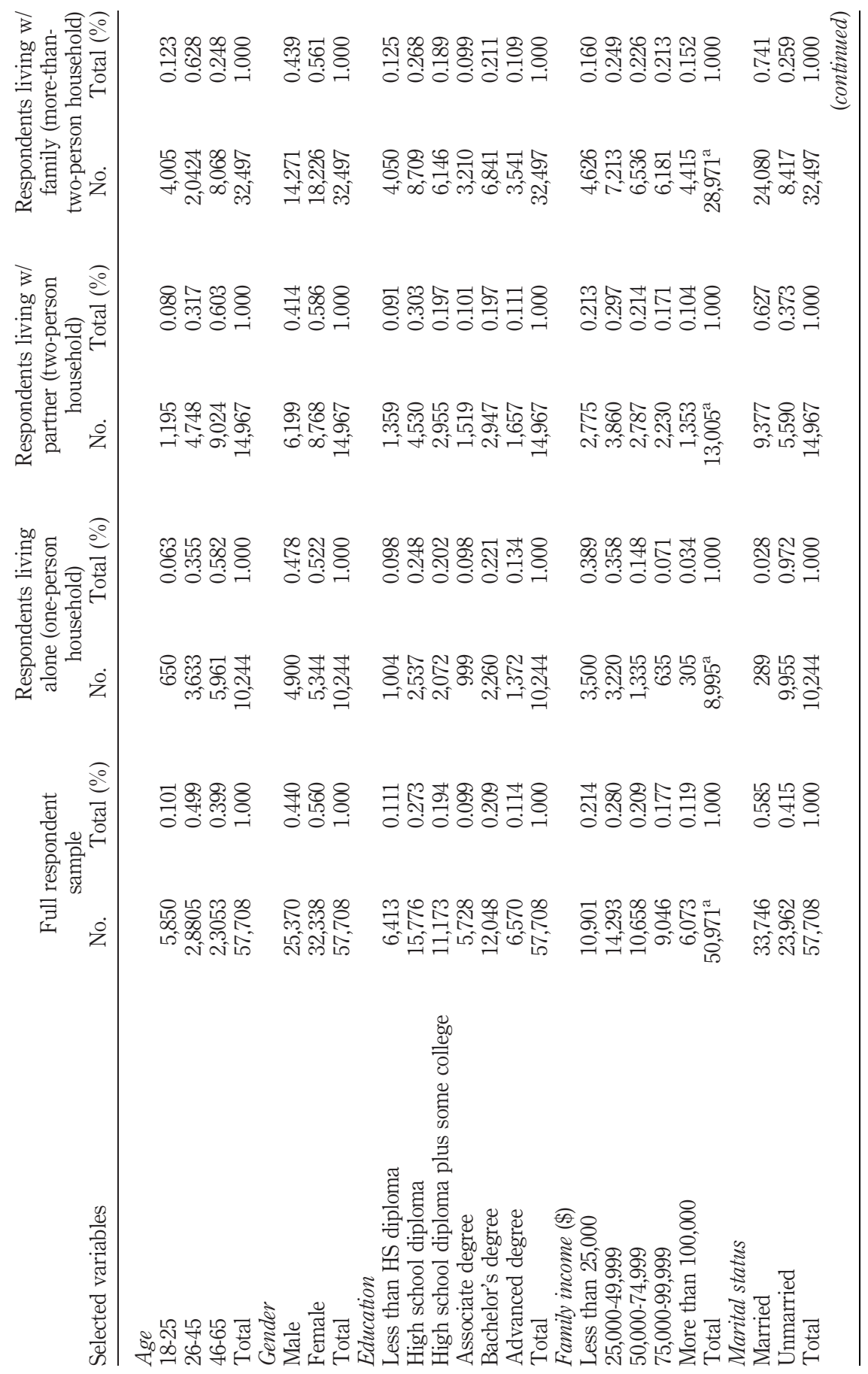




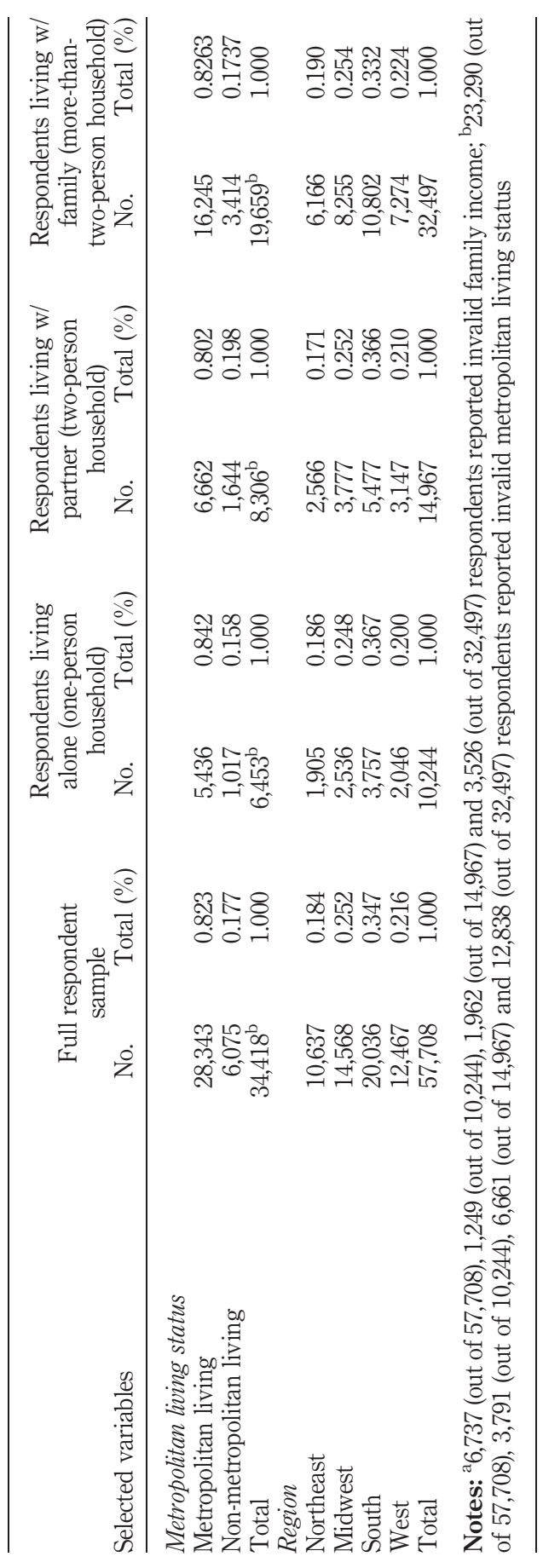

Food preparation choices

253

Table I. 


\section{CAER}

3,2

Table II.

Time allocation for selected activities by respondents

\section{4}

(1)

By full population

Obs Weighted average

(n) (minutes per day)
(2)

By participants

Weighted average (minutes per day)

Full respondents ( $n=57,708)$ (Time spent on selected activity)

Obs

(n)

Food-cooked-at-home ${ }^{\text {a }}$

Food-away-from-home

57,708

Work $^{\mathrm{b}}$

57,708

34.4

Family care

57,708

7.5

265.5

$\begin{array}{ll}57,708 & 39.2\end{array}$

Socializing, relaxing, and leisure

259.9

57,708

Respondents living alone (one-person

Food-cooked-at-home ${ }^{\text {a }}$

Food-away-from-home

household $)$
10,244 $(n=10,244)$

Work ${ }^{\mathrm{b}}$

10,244

10,244

Family care ${ }^{c}$

Socializing, relaxing, and leisure 10244

8.2

282.8

Respondents living w/partner (two-p

292.7

34,677

15,669

26,130

21,112

54,784

Socializing, relaxing, and leisure $\quad 14,967$

Family care
Food-cooked-at-home ${ }^{\mathrm{a}}$

Food-away-from-home

Work ${ }^{\mathrm{b}}$

Family care activity)

Food-cooked-at-home ${ }^{\text {a }} \quad 32,497$

Food-away-from-home

32,497

32,497

Work $^{\mathrm{b}}$

32,497

32,497

Socializing, relaxing, and leisure

32.7

8.4

269.3

10.7

275.3

usehold

37.3
6.8
260.1
61.5
245.3

245.3

Notes: aFood-cooked-at-home includes: (1) food and drink preparation, (2) food presentation, and (3) kitchen and food clean-up; ${ }^{b}$ working hours include Saturday and Sunday; ${ }^{c} 10,112$ (out of 10, 244) respondents spent zero on family care

the average-hours-per-day formula to ensure that: each group is correctly represented in the population; each day of the week is correctly represented for the sample month; and groups and days of the week are correctly represented for the sample month[8]. Column (1) in Table II shows the weighted average time spent on each activity by full-population (including those who spent zero minutes), while Column (2) shows the weighted average time spent on each activity by participants (excluding those who spent zero minutes). We focus on the analysis of the weighted average time spent on each activity by participants who engaged in the activity, shown in Column (2), focusing on the household level sample.

Table II shows that, among participants, households spend more time on preparing food-cooked-at-home as the number of the household members increases (45 minutes per day for one-person households, 57.9 minutes per day for two-person households, and 66.4 minutes per day for more-than-two-person households). This implies that households are seeking economies of scale in home cooking. The table further shows that fewer households consume food-away-from-home as the number of household members increases (30 percent of one-person households, 28 percent of two-person households, 
and 26 percent of more-than-two-person households). However, two-person households spend the most time on food-away-from-home, followed by more-than-two-person households and one-person households (29.6, 27.5, and 26.8 minutes per day, respectively). These results indicate that household size affects the time spent obtaining food-away-from-home. Further, the percentage of respondents who work is independent of household size, yet hours worked decrease as household size increases. Family care time depends heavily on the number of household members and socializing, relaxing and leisure time is about 260-309 minutes per day.

\section{Empirical strategy}

The objective of this paper is to examine how a respondent's preferences regarding nutrition (which relates to health) and luxury (which reflects wealth), the value of time, and family income affect that person's time allocation decision regarding the choice between food-cooked-at-home and food-away-from-home.

A substantial portion of respondents did not allocate time to food preparation on the date of the diary interview. Our selected sample is thus censored and consists of both zero value observations, which are generated by respondents who did not spend time on food preparation, and non-zero value observations, which are from those who spent time on this activity. To account for the qualitative differences between zero observations and continuous observations, we estimate the following equation using a Tobit model (Tobin, 1958):

$$
T_{i}^{*}=X_{i} \beta+\varepsilon_{i},
$$

where $\varepsilon_{i}$ is a mean zero individual error term and $T_{i}^{*}$ denotes the amount of time spent per day on food preparation. We use $T_{i}^{*}$ to represent the consumption of food-away-from-home relative to food-cooked-at-home (i.e. $\mathrm{k} / \mathrm{n}$ ), which is positively related to $\theta$ and $w$, and negatively related to $\alpha$, as implied in equations (8) and (9). Further, $X_{i}$ in equation (10) is a vector of exogenous variables of respondent characteristics, which include:

- education;

- family income;

- age;

- gender;

- race;

- ethnicity;

- hours worked per day;

- household size; and

- region.

We also control for marital status, metropolitan living status, and the season that the diary was completed. A detailed description of variables is shown in the Appendix.

One could argue that time allocation for food preparation is determined by the individual choice of whether or not to participate in this activity; in other words, respondents self-select regarding food preparation activity. To account for the nonrandom nature of our dataset, we also estimate the sample selection model (Heckman, 1979)[9].

\author{
Food preparation \\ choices \\ 255
}


CAER

3,2

\section{6}

We consider our random sample of $I$ observations. Equations for respondent $i$ are as follows:

$$
\begin{aligned}
& T_{1 i}^{*}=X_{1 i} \beta_{1}+\varepsilon_{1 i} \\
& T_{2 i}^{*}=X_{2 i} \beta_{2}+\varepsilon_{2 i}
\end{aligned} \quad(i=1, \ldots, I) .
$$

The sample selection model consists of: a participation equation, and a resultant outcome equation as follows:

$$
T_{1 i}=\left\{\begin{array}{l}
1 \quad \text { if } T_{1 i}^{*}>0 \\
0 \quad \text { if } T_{1 i}^{*} \leq 0^{\prime}
\end{array}\right.
$$

where $T_{1 i}^{*}$ determines whether or not respondent $i$ has spent time on food preparation:

$$
T_{2 i}=\left\{\begin{array}{ll}
1 & \text { if } T_{1 i}^{*}>0 \\
- & \text { if } T_{1 i}^{*} \leq 0^{\prime}
\end{array},\right.
$$

where $T_{2 i}^{*}$ is observed when $T_{1 i}^{*}=1$, whereas $T_{2 i}$ need not take on any value when $T_{1 i}^{*} \leq 0$, and it defines how many minutes per day are allocated to food preparation by respondent $i$.

The likelihood of time spent on food preparation being observed depends on the respondent's age, gender, race, ethnicity, education, family income, hours worked per day, marital status, household size, region, metropolitan living status, and the season, and thus the explanatory variables $\left(X_{1 i}\right)$ in the participation equation are the same as in equation (10). The actual time spent on food preparation by the respondent in $T_{2 i}^{*}$ is unlikely to depend on the region of residence once a respondent elects to participate in food preparation; hence the explanatory variables $\left(X_{2 i}\right)$ in the resultant outcome equation are the same as in the participation equation except that it excludes region.

The error terms $\varepsilon_{1 i}$ and $\varepsilon_{2 i}$ in equation (11) are assumed to have a joint normal distribution with a mean vector zero and variance-covariance matrix as:

$$
\Omega=\left[\begin{array}{ll}
\sigma \varepsilon_{1} \varepsilon_{1} & \sigma \varepsilon_{1} \varepsilon_{2} \\
\sigma \varepsilon_{2} \varepsilon_{1} & \sigma \varepsilon_{2} \varepsilon_{2}
\end{array}\right] .
$$

The sample selection model has the following likelihood function:

$$
L=\Pi\left\{\operatorname{Pr}\left[T_{1 i}^{*} \leq 0\right]\right\}^{1-T_{1 i}}\left\{f\left(T_{2 i} \mid T_{1 i}^{*}>0\right)^{*} \operatorname{Pr}\left[T_{1 i}^{*}>0\right]\right\}^{T_{1 i}},
$$

where the first term is the discrete contribution when $T_{1 i}^{*} \leq 0$, since $T_{1 i}=0$, and the second term is the continuous contribution when $T_{1 i}^{*}>0$. We define $T_{1 i}^{*}$ as the unobserved propensity to spend time on food preparation, whereas $T_{2 i}$ is the actual time spent on food preparation.

\section{Empirical results}

This section examines the results of the Tobit and the two-step Heckman's sample selection models to analyze how a respondent's preferences for nutrition (which relates 
to health) and luxury (which reflects wealth), both of which are influenced by education, Food preparation have an impact on food preparation. We also examine the effect of a respondent's value of time and selected socio-economic characteristics on food preparation choices. choices The analyses of time spent preparing food-cooked-at-home and obtaining food-away-from-home are conducted separately using the estimation results in Tables III and IV, respectively.

6.1 Empirical results for time spent preparing food-cooked-at-home

Table III shows that education is, in general, negatively related to time spent preparing food-cooked-at-home. Estimates also suggest that education increases the probability

\begin{tabular}{|c|c|c|c|}
\hline Independent variables & $\begin{array}{c}\text { Tobit } \\
\text { Estimated } \\
\text { coefficient }\end{array}$ & $\begin{array}{l}\text { Outcome equation } \\
\text { Estimated } \\
\text { coefficient }\end{array}$ & $\begin{array}{l}\text { two-step } \\
\text { Participation } \\
\text { equation } \\
\text { Estimated } \\
\text { coefficient }\end{array}$ \\
\hline mter & $-44.26^{* * *}(3.131)$ & $-51.03^{* * *}(15.538)$ & $-0.61^{* * *}(0.049)$ \\
\hline Education: high s & $-3.67^{* * *}(1.295)$ & $-5.94^{* * *}(1.472)$ & $0.029(0.021)$ \\
\hline $\begin{array}{l}\text { Education: high school diploma plus } \\
\text { some college }(0 / 1)\end{array}$ & $-4.39^{* * *}(1.382)$ & $-6.60^{* * *}(1.561)$ & $0.016(0.022)$ \\
\hline & $-3.72^{* *}(1.596)$ & $-6.70 * * *(1.837)$ & $0.06 * *(0.025)$ \\
\hline & $-2.165(1.437)$ & $-5.54 * * *(1.736)$ & $0.09 * * *(0.023)$ \\
\hline ) & $-1.440(1.632)$ & $-4.20 * *(1.942)$ & $0.09 * * *(0.026)$ \\
\hline & $-3.25 * * *(0.948)$ & $-3.75^{* * *}(1.074)$ & $-0.03 *(0.015)$ \\
\hline & $-7.14^{* * *}(1.074)$ & $-7.97 * * *(1.291)$ & $-0.06^{* * *}(0.017)$ \\
\hline & $-5.88^{* * *}(1.187)$ & $-5.95 * * *(1.402)$ & $-0.07 * * *(0.019)$ \\
\hline me: more than $\$ 100,000$ & $-6.76^{* * *}(1$. & 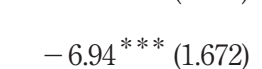 & \\
\hline & $39.08^{* * *}(1.344)$ & $\begin{array}{r}-0.94 * * *(1.016) \\
39.15 * *(4.464)\end{array}$ & $\begin{array}{r}-0.09 * * *(0.022) \\
0.55 * *(0.020)\end{array}$ \\
\hline & $44.00 * * *(1.406)$ & $45.58 * * *(4.820)$ & $0.60 * * *(0.021)$ \\
\hline & $48.37 * * *(0.7$ & $48.48 * * *(5.017)$ & $0.68 * * *(0.011)$ \\
\hline & $1.015(2.309)$ & $-0.748(2.6$ & $0.07^{* *}(0.036)$ \\
\hline & & & $-0.08^{* *}(0.039)$ \\
\hline & 15.49 & $20.94^{* * *}$ & $0.055(0.048$ \\
\hline & * (1.133) & $12.48 * * *(1.269)$ & $-0.04^{* *}(0.018)$ \\
\hline Hours worked per day & $-3.71^{* * *}(0.121)$ & $-4.12^{* * *}(0.312)$ & $-0.04^{* * *}(0.002)$ \\
\hline $\begin{array}{l}\text { Household size: household member }=2 \\
(0 / 1)\end{array}$ & $3.74^{* * *}(1.205)$ & $7.09 * * *(1.351)$ & $-0.018(0.019)$ \\
\hline $\begin{array}{l}\text { Household size: household member }=3 \\
(0 / 1)\end{array}$ & $11.16^{* * *}(1.311)$ & $15.42^{* * *}(1.574)$ & $0.07^{* * *}(0.021)$ \\
\hline $\begin{array}{l}\text { Household size: household member }=4 \\
(0 / 1)\end{array}$ & $15.12^{* * *}(1.387)$ & $20.28 * * *(1.757)$ & $0.11^{* * *}(0.022)$ \\
\hline $\begin{array}{l}\text { Household size: household member }=5 \\
\text { or more }(0 / 1)\end{array}$ & $21.85^{* * *}(1.500)$ & $28.74 * * *(1.975)$ & $0.15^{* * *}(0.024)$ \\
\hline & $-3.72^{* * *}(1.050)$ & $-(1.070)$ & $-0.05 * * *(0.017)$ \\
\hline$(0 / 1)$ & $-5.89^{* * *}(0.992)$ & - & $-0.08^{* * *}(0.016)$ \\
\hline & $-1.253(1.099)$ & - & $-0.001(0.018)$ \\
\hline & & Yes & Yes \\
\hline$R^{2} /$ Sigma/Mills & $76.146(0.243)$ & $77.113(12.662)$ & 77.113 (12.662) \\
\hline
\end{tabular}

Notes: $n=57,708$; significance at: ${ }^{*} 10,{ }^{* *} 5$ and ${ }^{* * *} 1$ percent level

Table III.

Parameter estimates of Tobit and two-step sample selection models time spent preparing food-cooked-at-home 


\section{CAER \\ 3,2}

Selection two-step

Outcome Participation

equation equation

Estimated Estimated

coefficient coefficient

\section{Table IV.}

Parameter estimates of Tobit and two-step sample selection models time spent obtaining food-away-from-home
Independent variables

Intercept

Education: high school diploma (0/1)

Education: high school diploma plus some college $(0 / 1)$

Education: associate degree (0/1)

Education: Bachelor's degree (0/1)

Education: advanced degree (0/1)

Family income: $\$ 25,000-49,999$ (0/1)

Family income: $\$ 50,000-74,999$ (0/1)

Family income: $\$ 75,000-99,999(0 / 1)$

Family income: more than $\$ 100,000(0 / 1)$

Age: 26-45 (0/1)

Age: 46-65 (0/1)

Gender: female (0/1)

Race: White $(0 / 1)$

Race: Black (0/1)

Race: Asian (0/1)

Ethnicity: Hispanic (0/1)

Hours worked per day

Household size: household member $=2$

$(0 / 1)$

Household size: household member $=3$

$(0 / 1)$

Household size: household member $=4$

$(0 / 1)$

Household size: household member $=5$ or more $(0 / 1)$

Region: Northeast $(0 / 1)$

Region: Midwest $(0 / 1)$

Region: South (0/1)

Other control variables

$R^{2} /$ Sigma/Mills
Notes: $n=57,708$; significance at: ${ }^{*} 10,{ }^{* *} 5$ and ${ }^{* * *} 1$ percent level

$$
\begin{aligned}
& -49.10^{* * *}(3.260) \quad 0.84^{* * *}(17.982)-0.70 * * *(0.051) \\
& 11.27^{* * *}(1.448) \quad 4.47^{*}(2.659) \quad 0.19 * * *(0.023) \\
& 16.11^{* * *}(1.504) \quad 6.11^{*}(3.454) \quad 0.27^{* * *}(0.024) \\
& 16.09 * * *(1.729) \quad 5.169(3.610) \quad 0.28 * * *(0.027) \\
& 19.31 * * *(1.560) \quad 7.39 *(3.979) \quad 0.33 * * *(0.025) \\
& 20.42 * * *(1.739) \quad 9.59 * *(4.009) \quad 0.33 * * *(0.028) \\
& 4.19 * * *(1.005) \quad 0.215(1.425) \quad 0.08 * * *(0.016) \\
& 9.52 * * *(1.118) \quad 3.252(2.152) \quad 0.17 * * *(0.018) \\
& 12.41^{* * *}(1.212) \quad 4.37^{*}(2.614) \quad 0.22^{* * *}(0.019) \\
& 15.43 * * *(1.406) \quad 6.33 * *(3.148) \quad 0.27 * * *(0.022) \\
& -12.10 * * *(1.301) \quad-3.378(2.791)-0.23 * * *(0.021) \\
& -15.72^{* * *}(1.378) \quad-3.696(3.536)-0.30 * * *(0.022) \\
& -3.17 * * *(0.746)-1.71 *(0.964)-0.05 * * *(0.012) \\
& 1.058(2.320) \quad-3.383(2.709) \quad 0.053(0.038) \\
& -18.23^{* * *}(2.537)-10.01^{* *}(4.216)-0.28^{* * *}(0.042) \\
& -4.055(3.079) \quad-2.723(3.563) \quad-0.060(0.050) \\
& -1.065(1.190) \quad 0.119(1.304) \quad-0.019(0.019) \\
& 0.56 * * *(0.127) \quad-0.059(0.191) \quad 0.011^{* * *}(0.002) \\
& -3.05^{* *}(1.236) \quad-0.137(1.525)-0.07^{* * *}(0.020) \\
& -10.84^{* * *}(1.355) \quad-5.51^{* *}(2.421)-0.18 * * *(0.021) \\
& -10.58^{* * *}(1.429) \quad-3.717(2.582)-0.20 * * *(0.023) \\
& -15.97^{* * *}(1.569) \quad-6.61^{*}(3.470)-0.28^{* * *}(0.025) \\
& \begin{array}{rll}
1.709(1.102) & - & 0.07^{* * * *}(0.017) \\
4.89^{* * *}(1.041) & - & 0.11^{* * *}(0.017)
\end{array} \\
& 2.43^{* *}(1.154) \quad-\quad 0.06 * *{ }^{*}(0.018) \\
& \text { Yes Yes Yes } \\
& 66.244(0.188) \quad 26.057(14.145) \quad 26.057 \text { (14.145) }
\end{aligned}
$$

of one's participating in food-cooked-at-home, while also reducing the time spent on this activity. For example, respondents with at least a bachelor's degree spend less time spent on this activity than those with an associate degree or less. These results reveal two important points. First, a high value of time (due to long working hours) and a high preference for luxury (due to higher education and higher market wages) outweigh nutritional concerns (trading nutrition or price for luxury), leading, overall, to reduced time spent preparing food-cooked-at-home. Second, a high preference for nutrition (related to high education) outweighs luxurious tastes (trading luxury for nutrition), leading less time spent on preparing food-cooked-at-home among those with at least a bachelor's degree relative to those with an associate degree. 
Similarly, household income is inversely related to time spent preparing Food preparation food-cooked-at-home. More precisely, higher income reduces both the probability of one's engaging in food-cooked-at-home and the actual time spent on this activity. For example, households earning more than $\$ 50,000$ spend less time on this activity (about six to eight minutes) compared to those earning less than $\$ 25,000$. These results indicate that a higher income increases the value placed on luxury or leisure relative to nutrition, and thus it leads to a reduction in both the likelihood of preparing food-cooked-at-home and the actual time spent on preparing food at home, substituting food-away-from-home. As expected, hours worked per day are inversely related to time spent preparing food-cooked-at-home, indicating that time-constrained respondents allocate less time to cooking at home.

On the other hand, respondents' age had a large and positive effect not only on their decision to engage in food-cooked-at-home but also on their actual time spent on this activity, and the effect becomes larger as age increases (Aguiar and Hurst, 2007). Similarly, larger households are more likely than smaller households to engage in food preparation at home and to spend more time on this activity. This result suggests that a large family is aiming for economies of scale in home production (Floro and Miles, 2003) and that those with children and/or older people might be more nutrition-conscious (trading luxury for nutrition) and thus are likely to consume more food-cooked-at-home (Binkley, 2006; Stewart et al., 2005; Blisard et al., 2002; Glanz et al., 1998; Glanz et al., 1994), which is consistent with our prediction. As expected, women spent more time (about 48 minutes) preparing food-cooked-at-home than men. This result supports the existing notion in which women still make most food-related decisions (Redman, 1980).

Table III further shows that there is a large variation in time spent preparing food-cooked-at-home by race and ethnicity. Estimates indicate that being Black or Hispanic reduces the probability of one's preparing food-cooked-at-home, yet the actual time spent on this activity among Blacks is not significantly different from those of "other" races, while Hispanics spend more time (eight minutes in Tobit and 12 minutes in the Heckman's sample selection model) than their counterparts. On the other hand, White are more likely to spend more time to prepare food-cooked-at-home than "other" races, yet the actual time spent on this activity among Whites is not significantly different from their counterparts. Asians are not more likely to prepare food-cooked-at-home than others, but their time spent on this activity is larger (15 minutes in Tobit and 21 minutes in the Heckman's sample selection model). These results suggest that Asians and Hispanics prefer to allocate more time to food preparation at home and to consume food-cooked-at-home, which may reflect the fact that they place a high value on nutrition (which is related to education) and/or set a low value on luxury (which results from budget consciousness). Alternatively, Asians and Hispanics are likely to follow their particular cultural traditions in which families eat at home, and, in turn, they are likely to spend more time cooking at home (Mancino and Newman, 2007).

\subsection{Empirical results for time spent obtaining food-away-from-home}

Table IV shows that education not only increases the probability of one's selecting food-away-from-home but also the actual time spent on this activity, and that the effect is more prominent for those with higher education. For example, respondents with an advanced degree spent the most time on this activity (20 minutes in Tobit and ten minutes in the Heckman's sample selection model) relative to those without a high 
CAER

3,2

260 school diploma. These results highlight the following two points. First, estimates confirm the existing literature in which more educated individuals have larger food-away-from-home expenditures (Angulo et al., 2007; Horton and Campbell, 1991). Second, a high taste for luxury, derived from a higher education plus higher market wages, dominates nutritional concerns, leading to increased time spent obtaining food-away-from-home (and reduced time spent preparing food-cooked-at-home).

Correspondingly, higher family income increases both the probability of one's consuming food-away-from-home and the actual time spent on this activity. Households earning more than $\$ 100,000$ spent the most time on this activity followed by those earning $\$ 75,000-99,999$ (15 minutes and 12 minutes, respectively, in Tobit, and six and four minutes, respectively, in the Heckman's sample selection model). These results suggest that high-income households place more value on luxury (trading price for luxury), and, in turn, increase time spent obtaining food-away-from-home. This result supports the existing positive relationship between family income and food consumption outside the home (Blaylock et al., 1999; Redman, 1980).

In contrast, women have a lower probability of selecting food-away-from-home and spend less time on this activity relative to men. Similarly, a large household size reduces both the frequency of selecting food-away-from-home and the actual time spent on this activity. Respondents with families of more than five members, for example, spend less time (16 minutes in Tobit and seven minutes in the Heckman's sample selection model) on food-away-from-home relative to those living alone. These results support the existing negative relationship between household size and food-away-from-home consumption due to the financial burden of dining out (Redman, 1980).

Within race and ethnic groups, Blacks consume less food-away-from-home and spend less time on this activity than those of "other" races (18 minutes in Tobit and ten minutes in the Heckman's sample selection model). These results confirm that Blacks, who have relatively low incomes (Diez-Roux et al., 1999; Turrell, 1996; Williams and Collins, 1995; Kinsey, 1994) and spend less of their income on food (Kinsey, 1994), consume less food-away-from-home, and thus spend less time dining out. Whites, Asians, and Hispanics showed no effect. Further, age reduces the probability of selecting food-away-from-home, while hours worked per day increases it; however, the relationship between age and actual time spent on this activity is rather unclear.

\section{Conclusions}

This paper examines how an individual's preferences regarding nutrition (which relate to health) and luxury (which reflects wealth) affect their time allocation decisions related to food preparation, especially the choice between food-cooked-at-home and food-away-from-home. A time allocation model is developed and empirically tested with Tobit and Heckman's sample selection models using the 2003-2007 ATUS data to analyze the allocation of non-market hours to food preparation choices.

Estimates reveal several important findings. First, family income and hours worked per day affect the frequency of selecting and the actual time spent preparing or obtain both food-cooked-at-home (negatively) and food-away-from-home with respect to the latter. Luxury-conscious and time-constrained individuals (e.g. those with high wealth and/or long market hours) allocate more time to obtaining food-away-from-home, suggesting that a trade-off exists between nutrition (or price) and luxury. 
Second, education reduces the actual time spent on food-cooked-at-home even though it increases the probability of cooking food at home, and it increases both the likelihood of selecting and the actual time spent on food-away-from-home. Highly educated choices individuals (with high wages and/or long market hours) allocate more time to obtaining food-away-from-home, another confirmation that a trade-off exists between nutrition (or price) and luxury although the effect of nutritional preference cannot be ignored.

Finally, age, female gender, and household size increase not only the probability of preparing food-cooked-at-home but also the actual time spent preparing it, while they reduce the likelihood of selecting food-away-from-home as well as the time spent obtaining it. Nutrition-conscious individuals (e.g. older people) and budget-constrained individuals (e.g. large households and low-income households) allocate more time to food-cooked-at-home, indicating that a trade-off exists between luxury and nutrition (or price). Finally, a large variation in the time allocation decision exists when race and ethnicity are considered.

The results of this study confirm that the time allocation decisions regarding food preparation are largely affected by an individual's luxury preference $(\theta)$, nutritional consciousness $(\alpha)$, and the value of time, all of which are influenced by education. The findings from this study indicate factors that influence consumers' time allocation decisions regarding food choice and their current food preparation behavior, and thus provide useful insights to nutritionists, dietitians, health practitioners, and policy makers for finding better ways to improve nutritional education, food choices and dietary habits that promote healthier diets and eating habits for Americans. The findings of this study are also useful for developing nutritional education programs in many Asian countries, such as China, that are increasingly adopting Western-style food and average caloric intakes.

\section{Notes}

1. Prepared-food, such as fast food, is less expensive and less nutrient than food-away-from-home (Binkley, 2006). Food-away-from-home is lower nutritional quality than food-cooked-at-home (Schroeter and Lusk, 2008; Lin and Frazao, 1997) because restaurant meals contain higher fat and calories than food-cooked-at-home (Lin et al., 1999; Blaylock et al., 1999). Further, nutrition conscious individuals are likely to use nutritional labels while shopping and at home (Nayga et al., 1998) and consume more food-cooked-at-home.

2. The weighted average daily time spent on purchasing prepared-food in the full sample is 1.2 minutes. About 12.5 percent (or 7,225 out of 57,708 ) of population is engaged in this activity based on the data sample in this study.

3. Take the first-order conditions of the Lagrangian function with respect to $l_{w}$ and $l_{0}$, and we obtain $\lambda_{1}=1 / w$ and $\lambda_{2}=1$.

4. While the amount of time required to prepare food-cooked-at-home $\left(t_{n}(N)\right)$ is increasing at a diminishing rate $\left(\left(t_{n}^{\prime}(N)>0\right.\right.$ and $\left.t_{n}^{\prime \prime}(N)<0\right)$, the elasticity of time demand with respect to family size is less than one, implying that $t_{n}(N) / N$ decrease with family size $(N)$.

5. The American Time Use Survey Users Guide: Understanding ATUS 2003-2007 is sponsored by the Bureau of Labor Statistics (BLS, 2009), conducted by the US Census Bureau.

6. Time use categories include personal care (1), household activities (2), caring for and helping household and non-household members $(3,4)$, working and work-related activities (5), education (6), consumer purchases (7), professional and personal care services (8), household 
CAER

3,2

262 services (9), government services and civic obligations (10), eating and drinking (11), socializing, relaxing and leisure (12), sports, exercise, and recreation (13), religious and spiritual activities (14), volunteer activities (15), telephone calls (16), and traveling (18). A detailed description is available in the ATUS Activity Lexicon 2003-2007 (BLS, 2009).

7. Time spent purchasing prepared-food (or "all other goods" in equation (3)) is neglected because the weighted average daily time spent on this activity in the full sample is at minimal and only 12.5 percent of the full population is engaged in this activity.

8. A detailed description is available in the American Time Use Survey Users Guide: Understanding ATUS 2003-2007 (BLS, 2009).

9. The sample selection model is also known as the type 2 Tobit model (Amemiya, 1985), the Probit selection model (Wooldridge, 2002) or the bivariate sample selection model (Cameron and Trivedi, 2005).

\section{References}

Aguiar, M. and Hurst, E. (2007), "Lifecycle prices and production", The American Economic Review, Vol. 97 No. 5, pp. 1533-59.

Amemiya, T. (1985), “Tobit models”, Advanced Econometrics, Harvard University Press, Cambridge, MA, pp. 360-411.

Angulo, A.M., Gil, J.M. and Mur, J. (2007), "Spanish demand for food away from home: analysis of panel data", Journal of Agricultural Review, Vol. 58 No. 2, pp. 289-307.

Becker, G.S. (1965), “A theory of the allocation of time”, The Economic Journal, Vol. 75 No. 299, pp. 493-517.

Binkley, J.K. (2006), "The effect of demographic, economic, and nutrition factors on the frequency of food away from home", The Journal of Consumer Affairs, Vol. 40 No. 20, pp. 372-91.

Blaylock, J., Smallwood, D., Kassel, K., Variyam, J. and Aldrich, L. (1999), "Economics, food choices, and nutrition", Food Policy, Vol. 23 Nos 2/3, pp. 269-86.

Blisard, W.N. and Stewart, H. (2007), "Food spending in American households, 2003-2004", Economic Information Bulletin No 23, United States Department of Agriculture, Washington, DC.

Blisard, N., Lin, B.-H., Cromartie, J. and Ballenger, N. (2002), “America's changing appetite: food consumption and spending to 2020", Food Review, Vol. 25 No. 1, pp. 1-9.

BLS (2009), American Time Use Survey Users Guide: Understanding ATUS 2003-2007, Bureau of Labor Statistics, Washington, DC, available at: www.bls.gov/tus/datafiles_0307.htm

Cameron, C.A. and Trivedi, P.K. (2005), "Tobit and selection models", Microeconometics: Methods and Applications, Cambridge University Press, New York, NY, pp. 529-72.

Campo, I.S. and Beghin, J.C. (2006), "Dairy food consumption, supply, and policy in Japan”, Food Policy, Vol. 31 No. 3, pp. 228-37.

Carlson, K.A. and Gould, B.W. (1994), "The role of health knowledge in determining dietary fat intake", Review of Agricultural Economics, Vol. 16 No. 3, pp. 373-86.

Carlson, K.A., Kinsey, J. and Nadav, C. (2002), “Consumers' retail source of food: a cluster analysis", Family Economics and Nutrition Review, Vol. 14 No. 2, pp. 11-20.

Curtis, K.R., McCluskey, J.J. and Wahl, T.I. (2007), "Consumer Preference for Western-Style Convenience Foods in China”, China Economic Review, Vol. 18 No. 1, pp. 1-14.

Darian, J.C. and Klein, S.W. (1989), "Food expenditure patterns of working-wife families: meals prepared away from home versus convenience foods", Journal of Consumer Policy, Vol. 12 No. 2, pp. 139-64. 
Diez-Roux, A.V., Nieto, F.J., Caulfield, L., Tyroler, H.A. and Watson, M.S. (1999), "Neighborhood differences in diet: the atherosclerosis risk in communities (ARIC) study", Journal of Epidemiology and Community Health, Vol. 53, pp. 55-63.

Floro, M.S. and Miles, M. (2003), “Time use, work and overlapping activities: evidence from Australia”, Cambridge Journal of Economics, Vol. 27 No. 6, pp. 881-904.

Glanz, K., Basil, M., Maibach, E., Goldberg, J. and Snyder, D. (1998), "Why American eat what they do: taste nutrition, cost, convenience, and weight control concerns as influences on food consumption", Journal of the American Dietetic Association, Vol. 98 No. 10, pp. 1118-26.

Glanz, K., Kristal, R.E., DiClemente, C.C., Heimendinger, J., Linnan, L. and McLerran, D.F. (1994), "Stages of change in adopting healthy diets: fat, fiber, and correlates of nutrient intake", Health Education Quarterly, Vol. 21 No. 4, pp. 499-519.

Heckman, J.J. (1979), "Sample selection bias as a specification error”, Econometrica, Vol. 47 No. 1, pp. 153-61.

Horton, S. and Campbell, C. (1991), "Wife's employment, food expenditures, and apparent nutrient intake: evidence from Canada", American Journal of Agricultural Economics, Vol. 73 No. 3, pp. 784-94.

Kinsey, J.D. (1994), "Food and families' socioeconomic status", The Journal of Nutrition, Vol. 124, pp. 1878S-85S.

Lee, J.-Y. and Brown, M.G. (1993), "Food expenditure at home and away from home in the United States - a switching regression analysis", The Review of Economics and Statistics, Vol. 68 No. 1, pp. 142-7.

Lin, B.H. and Frazao, E. (1997), "Nutritional quality of foods at and away from home”, Food Review, Vol. 21, pp. 33-40.

Lin, B.H., Guthrie, J. and Frazao, E. (1999), "Nutrient contribution of food away from home", Agriculture Information Bulletin, No. 750.

McCracken, V.A. and Brandt, J.A. (1987), "Household consumption of food-away-from-home: total expenditure and by type of food facility", American Journal of Agricultural Economics, Vol. 69 No. 2, pp. 274-84.

Ma, H., Huang, J., Fuller, F. and Rozelle, S. (2006), "Getting rich and eating out: consumption of food away from home in urban China", Canadian Journal of Agricultural Economics, Vol. 54 No. 1, pp. 101-19.

Mancino, L. and Newman, C. (2007), "Who has time to cook? How family resources influence food preparation”, Economic Research Report No. 40, United States Department of Agriculture, Washington, DC.

Martinez, S. and Stewart, H. (2003), "From supply push to demand pull", Amber Waves, Economic Research Service, United States Department of Agriculture, available at: www. ers.usda.gov/AmberWaves/November03/Features/supplypushdemandpull.htm (accessed November 2010).

Nayga, R.M. Jr, Lipinski, D. and Savur, N. (1998), “Consumers' use of nutritional labels while food shopping and at home”, The Journal of Consumer Affairs, Vol. 32 No. 1, pp. 106-20.

Pietrykowski, B. (2004), "You are what you eat: the social economy of the slow food movement", Review of Social Economy, Vol. 62 No. 3, pp. 307-21.

Popkin, B.M., Siega-Riz, A.M. and Haines, P.S. (1996), "A comparison of dietary trends among racial and socioeconomic groups in the United States", The New England Journal of Medicine, Vol. 335 No. 10, pp. 716-20. 
CAER

3,2

264
Prochaska, F.J. and Schrimper, R.A. (1973), "Opportunity cost of time and other socioeconomic effects on away-from-home food consumption", American Journal of Agricultural Economics, Vol. 55 No. 4, pp. 595-603.

Ramezani, C.A. and Claudia, R. (1995), "Health knowledge and nutritional adequacy of female heads of households in the United States", The Journal of Consumer Affairs, Vol. 29 No. 2, pp. 381-402.

Redman, B.J. (1980), “The impact of women's time allocation on expenditure for meals away from home and prepared food", American Journal of Agricultural Economics, Vol. 62 No. 2, pp. 234-7.

Rimal, A.P. (2002), "Factor affecting meat preferences among american consumers", Family Economics and Nutrition Review, Vol. 14 No. 2, pp. 36-43.

Schroeter, C. and Lusk, J.L. (2008), "Economic factors and body weight: an empirical analysis", Journal of Agricultural and Applied Economics, Vol. 40 No. 2, pp. 523-38.

Stewart, H. and Yen, S.T. (2004), "Changing household characteristics and the away-from-home food market: a censored equation system approach", Food Policy, Vol. 29 No. 6, pp. 643-58.

Stewart, H., Blisard, N., Jolliffe, D. and Bhuyan, S. (2005), "The demand for food away from home: do other preferences compete with our desire to eat healthfully?", Journal of Agricultural and Resource Economics, Vol. 30 No. 3, pp. 520-36.

Tobin, J. (1958), "Estimation of relationships for limited dependent variables", Econometrica, Vol. 26 No. 1, pp. 24-36.

Turrell, G. (1996), "Structural, material, and economic influences on the food-purchasing choices of socioeconomic groups", Australian and New Zealand Journal of Public Health, Vol. 20 No. 6, pp. 611-17.

Veeck, A. and Veeck, G. (2000), "Consumer segmentation and changing food purchase patterns in Nanjing, PRC”, World Development, Vol. 28 No. 3, pp. 457-71.

Williams, D.R. and Collins, C. (1995), "US socioeconomic and racial differences in health: patterns and explanations”, Annual Review of Sociology, Vol. 21, pp. L349-89.

Wooldridge, J.M. (2002), "Sample selection, attrition, and stratified sampling", Econometric Analysis of Cross Section and Panel Data, The MIT Press, Cambridge, MA, pp. 551-601.

Yen, S.T. (1993), "Working wives and food away from home: the box-cox double hurdle model", American Journal of Agricultural Economics, Vol. 75 No. 4, pp. 884-95.

\section{Further reading}

USBLS (2009b), American Time Use Survey Activity Lexicon 2003-2007, United States Bureau of Labor Statistics, Washington DC.

USBLS (2009a), American Time Use Survey Data: 2003-2000, United States Bureau of Labor Statistics, Washington, DC, available at: www.bls.gov/tus/datafiles_0307.htm

USBLS (2009c), American Time Use Survey User's Guide: Understranding ATUS 2003-2007, United States Bureau of Labor Statistics, Washington, DC.

\section{Corresponding author}

Chu-Ping Lo can be contacted at: cplo@ntu.edu.tw

To purchase reprints of this article please e-mail: reprints@emeraldinsight.com Or visit our web site for further details: www.emeraldinsight.com/reprints 


\begin{tabular}{|c|c|c|c|c|}
\hline Variable description & Notation & $\begin{array}{l}\text { Unweighted } \\
\text { means }\end{array}$ & Min. & Max. \\
\hline \multicolumn{5}{|l|}{ Outcome measures } \\
\hline Total time spent preparing food-cooked-at-home & tfprep1 & 38.7783 & 0 & 975 \\
\hline $\begin{array}{l}\text { Total time spent obtaining food-away-at-home } \\
\text { Explanatory variables }\end{array}$ & tfprep2 & 8.2346 & 0 & 1220 \\
\hline Age of respondent: 18-25 (0/1) & age1 & 0.1014 & 0 & 1 \\
\hline Age of respondent: $26-45(0 / 1)$ & age2 & 0.4992 & 0 & 1 \\
\hline Age of respondent: 46-65 (0/1) & age3 & 0.3995 & 0 & 1 \\
\hline Gender of respondent: male (0/1) & men & 0.4396 & 0 & 1 \\
\hline Gender of respondent: female $(0 / 1)$ & women & 0.5604 & 0 & 1 \\
\hline Race of respondent: White $(0 / 1)$ & race1 & 0.8253 & 0 & 1 \\
\hline Race of respondent: Black (0/1) & race2 & 0.1212 & 0 & 1 \\
\hline Race of respondent: Asian (0/1) & race3 & 0.0304 & 0 & 1 \\
\hline Race of respondent: other $(0 / 1)$ & race4 & 0.0231 & 0 & 1 \\
\hline Ethnicity of respondent: Hispanic $(0 / 1)$ & ethnic1 & 0.1308 & 0 & 1 \\
\hline Ethnicity of respondent: non-Hispanic (0/1) & ethnic2 & 0.8692 & 0 & 1 \\
\hline Education of respondent: less than HS diploma (0/1) & education0 & 0.1111 & 0 & 1 \\
\hline Education of respondent: HS diploma $(0 / 1)$ & education1 & 0.2734 & 0 & 1 \\
\hline Education of respondent: HS diploma plus some college $(0 / 1)$ & education2 & 0.1936 & 0 & 1 \\
\hline Education of respondent: associate degree $(0 / 1)$ & education3 & 0.0993 & 0 & 1 \\
\hline Education of respondent: Bachelor's degree $(0 / 1)$ & education4 & 0.2088 & 0 & 1 \\
\hline Education of respondent: advanced degree $(0 / 1)$ & education5 & 0.1138 & 0 & 1 \\
\hline Hours worked per day & workhour & 4.3106 & 0 & 22.86 \\
\hline Marital status of respondent: married (0/1) & marital1 & 0.5848 & 0 & 1 \\
\hline Marital status of respondent: unmarried (0/1) & marital 2 & 0.4152 & 0 & 1 \\
\hline Family income of respondent: less than $\$ 25,000(0 / 1)$ & faminc0 & 0.1889 & 0 & 1 \\
\hline Family income of respondent: $\$ 25,000-49,999(0 / 1)$ & faminc1 & 0.2477 & 0 & 1 \\
\hline Family income of respondent: $\$ 50,000-74,999(0 / 1)$ & faminc2 & 0.1847 & 0 & 1 \\
\hline Family income of respondent: more than $\$ 100,000(0 / 1)$ & faminc3 & 0.1568 & 0 & 1 \\
\hline Family income of respondent: $\$ 50,000-74,999(0 / 1)$ & faminc4 & 0.1052 & 0 & 1 \\
\hline Household size of respondent: member $=1(0 / 1)$ & hhmember1 & 0.1775 & 0 & 1 \\
\hline Household size of respondent: member $=2(0 / 1)$ & hhmember2 & 0.2594 & 0 & 1 \\
\hline Household size of respondent: member $=3(0 / 1)$ & hhmember3 & 0.2058 & 0 & 1 \\
\hline Household size of respondent: member $=4(0 / 1)$ & hhmember4 & 0.2173 & 0 & 1 \\
\hline Household size of respondent: member $=5$ or more $(0 / 1)$ & hhmember5 & 0.1400 & 0 & 1 \\
\hline Metropolitan living status of respondent: Metropolitan (0/1) & metro1 & 0.4911 & 0 & 1 \\
\hline Metropolitan living status of respondent: & & & & \\
\hline non-metropolitan (0/1) & metro2 & 0.1053 & 0 & 1 \\
\hline Season: diary day of respondent: winter (0/1) & winter & 0.2630 & 0 & 1 \\
\hline Season: diary day of respondent: spring (0/1) & spring & 0.2489 & 0 & 1 \\
\hline Season: diary day of respondent: summer $(0 / 1)$ & summer & 0.2438 & 0 & 1 \\
\hline Season: diary day of respondent: fall (0/1) & fall & 0.2442 & 0 & 1 \\
\hline Region of respondent: Northeast $(0 / 1)$ & region1 & 0.1843 & 0 & 1 \\
\hline Region of respondent: Midwest (0/1) & region2 & 0.2524 & 0 & 1 \\
\hline Region of respondent: South $(0 / 1)$ & region3 & 0.3472 & 0 & 1 \\
\hline Region of respondent: West $(0 / 1)$ & region4 & 0.2160 & 0 & 1 \\
\hline
\end{tabular}

Table AI. Variable description, unweighted mean, and maximum and minimum: 2003-2007 